\title{
Psychometric analysis of the comfort scale for family members of people in critical health condition
}

\author{
Análise psicométrica da escala de conforto para familiares de pessoas em estado crítico de saúde \\ Análisis psicométrico de la escala de confort para famílias de personas em un estado de salud crítico
}

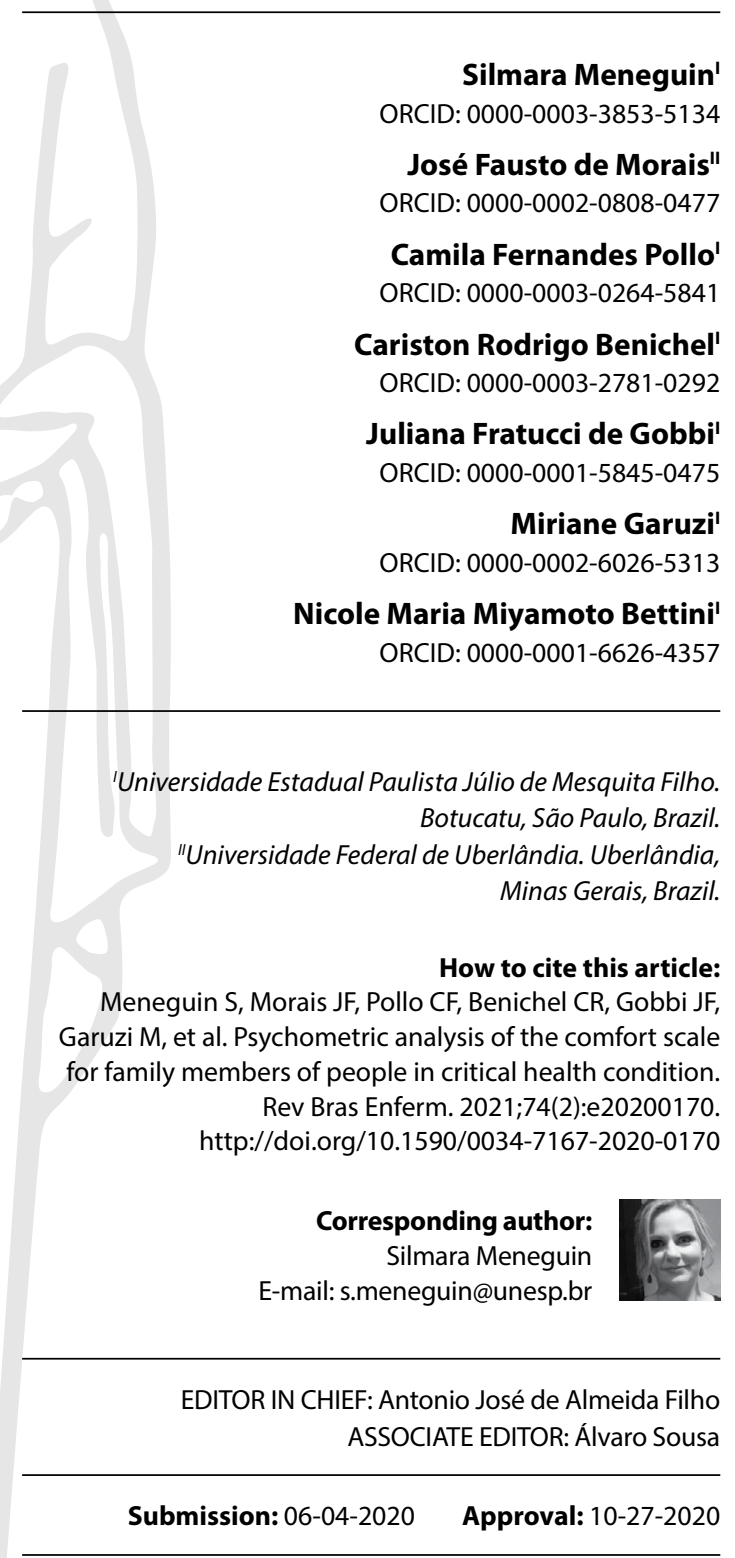

\begin{abstract}
Objectives: to assess the reliability and validity of the 46 items version of the comfort scale for family members of people in critical condition. Methods: a methodological study, carried out with 278 family members of critically ill patients, admitted to adult and pediatric intensive care units, in a city in the interior of the state of São Paulo, in Brazil. The analyzes were based on the Classical Test Theory and Item Response Theory. Results: Horn's parallel analysis and exploratory and confirmatory factor analysis did not identify the scale's unidimensionality nor the tridimensionality. The maximum factor loads were positive. The scale proved to be reliable ( $\alpha=0.93$ and $\Omega=0.63$ ), most item-total correlations were greater than 0.28 and the discrimination coefficients were greater than one. Conclusions: the scale showed satisfactory reliability and relative construct validity. However, the recommended tridimensional structure for the scale has not been confirmed.

Descriptors: Psychometrics; Validation Study; Family; Nursing; Intensive Care Units.
\end{abstract}

\section{RESUMO}

Objetivos: avaliar a confiabilidade e a validade da versão com 46 itens da escala de conforto para familiares de pessoas em estado crítico. Métodos: estudo metodológico, realizado com 278 familiares de pacientes críticos, internados em unidades de terapia intensiva adulto e pediátrica, do interior de São Paulo, Brasil. As análises foram baseadas na Teoria Clássica dos Testes e na Teoria de Resposta ao Item. Resultados: a análise paralela de Horn e as análises fatorial exploratória e confirmatória não identificaram a unidimensionalidade nem a tridimensionalidade da escala. As cargas fatoriais máximas foram positivas. A escala se mostrou confiável ( $\alpha=0,93$ e $\Omega=0,63$ ), a maioria das correlações item-total foram superiores a 0,28 e os coeficientes de discriminação maiores que um. Conclusões: a escala apresentou confiabilidade satisfatória e relativa validade de construto. No entanto, a estrutura tridimensional recomendada para a escala não foi confirmada.

Descritores: Psicometria; Estudos de Validação; Família; Enfermagem; Unidades de Terapia Intensiva.

\section{RESUMEN}

Objetivos: evaluar la confiabilidad y validez de la versión con 46 ítems de la escala de comodidad para familiares de personas en estado crítico. Métodos: estudio metodológico, realizado con 278 familiares de pacientes críticos, ingresados en unidades de cuidados intensivos de adultos y pediátricos, en el interior de São Paulo, Brasil. Los análisis se basaron en la teoría clásica de los tests y la teoría de respuesta a los ítems. Resultados: el análisis paralelo de Horn y el análisis factorial exploratorio y confirmatorio no identificaron la unidimensionalidad o tridimensionalidad de la escala. Las cargas factoriales máximas fueron positivas. La escala demostró ser confiable ( $\alpha=0,93$ e $\Omega=0,63$ ), la mayoría de las correlaciones ítem-total fueron mayores a 0.28 y los coeficientes de discriminación fueron mayores a uno. Conclusiones: la escala mostró una fiabilidad satisfactoria y una validez de constructo relativa. Sin embargo, no se ha confirmado la estructura tridimensional recomendada.

Descriptores: Psicometría; Estudio de Validación; Familia; Enfermería; Unidades de Cuidados Intensivos. 


\section{INTRODUCTION}

Comfort is a holistic, subjective and multidimensional concept affected by physical, environmental, social and psycho-spiritual contexts, which changes in time and space $^{(1)}$. It results from the interactions that the individual establishes with himself/herself, with those around him/her and with the situations he/she faces in the process of illness and health care ${ }^{(2-3)}$.

In intensive care units (ICUs), family members of critically ill patients have linked comfort to the existing infrastructure in the hospital environment, as well as the possibility of staying along with the patient, effective communication, psychological support and flexibility in the visits ${ }^{(4-5)}$.

However, this model of hospital care ends up forcing restrictive behaviors that, besides not allowing care to patients in all its aspects, disregards the needs of the family member as a person and individual worth of care.

A fact that contributes to the perception of comfort also extends the ability and coping strategies used by the family, by their previous experiences with hospital admissions or with the illness itself, along with the position that the relative has in the family context ${ }^{(6)}$.

The admission of a patient to the ICU causes changes in the family's routine, which had a sudden break of coexistence and the needs altered. Also, the anguish caused by the possibility of loss and separation, besides the length of hospitalization of critically ill patients, are factors that interfere in family dynamics ${ }^{(7)}$.

In the nursing practice environment, the term comfort is widely used in the daily language of nursing professionals, often related to the physical dimension of the ill individual, and has been an important element of the health promotion and comprehensive care process, given the need to reduce people's suffering, in all contexts of health care $^{(2,8)}$.

However, assessing family members' comfort has been a challenge, not only due to the variety of factors that may interfere with the perception of this concept, but also due to the scarcity of instruments available in the literature. There is only one other instrument, translated and validated into Portuguese available in the literature aimed at assessing the comfort of caregivers of cancer patients ${ }^{(9)}$.

This was the fact which inspired, in the year 2011, researchers from a Brazilian public university to develop the Comfort Scale for Family Members of People in Critical Health Condition (ECONF). The preliminary version of the instrument had 62 items, distributed on a six-point (or levels) Likert scale, being: 0- not applicable, 1- not comfortable at all, 2-not very comfortable, 3- more or less comfortable, 4 - very comfortable and 5 - totally comfortable. Each of the 62 items was weighed increasingly, that is, the higher the value attributed to the items, the greater the degree of comfort. These items were determined after a content analysis carried out by a group of judges (specialists and family members) and were distributed in 7 dimensions: safety (14 items), embracement (12 items), information (12 items), social/spiritual support ( 4 items), closeness (4 items), convenience (7 items) and self and routine integration ( 9 items) $)^{(5)}$.

Following the validation process, the instrument was applied to a sample of 274 family members of adult patients in critical condition, admitted to six ICUs of three public hospitals in the state of Bahia(10). The data were analyzed using the Classical Test Theory (CTT) and the Item Response Theory (IRT) using the Rasch model. The analysis of the items by the CTT showed a high Cronbach's alpha coefficient (a) indicating the scale's reliability $(a=0,92)$. The item discrimination analysis, based on the Item-Total Correlation (ITC), showed that except for items 12, 27 and 35, all items exhibited adequate ITC $(>0.20)$. The analysis of the items by the TRI-Model Rasch (analysis of the infit, outfit and difficulty) showed that most of the items were answered within the expected standard (average infit and outfit in the range of 0.7 to 1.3 and absolute difficulty lower to 1$)^{(5)}$.

After analysis by CTT and TRI, 16 items were excluded from the scale (criteria such as ITC $<0.2$, Overfit on infit or outfit, presence of DIF and factorial load $<0.30$ were used to exclude items) achieving a final scale with 46 items and three factors called Safety (SAF) with 22 items, Support (SUP) with 18 items and Family and relative? interaction (INT) with 6 items. The scale, called ECONF-46, kept the high alpha coefficient $(\alpha=0.92)$ and item-total correlation within the expected parameter (ITC $>0.2)$. The SAF factor showed very good internal consistency ( $\alpha=0.89$ ) with ITC ranging from 0.31 (item 21) to 0.67 (item 41); the SUP factor showed high internal consistency ( $a=0.88$ ) with ITC ranging from 0.34 (item 31) to 0.66 (item 57); the INT factor showed satisfactory internal consistency $(a=0.77)$ with ITC ranging from 0.43 (item 29) to 0.63 (item 32) (10). The rotation procedures adopted were orthogonal (Varimax), oblique and the matrix of polychoric correlations were also used. Thus, a version of the study with 46 of the 62 items, grouped in three dimensions: SAF, SUP and INT was made available at the end of the completion of a graduate school program ${ }^{(5)}$.

Subsequently, an analysis of main components about the 62 items of the same instrument, only by CTT showed a structure of 4 factors and 7 items that did not present criteria of permanence in the model. The 4 factors, called safety ( 20 items), support ( 21 items), family/relative interaction (7 items) and self-interaction and routine interaction ( 7 items), constituted a scale with 55 items, here called ECONF-55. The reliability analysis showed adequate values for the scale $(\alpha=0.92)$ and for its Safety dimension ( $\alpha=0.89)$, Support ( $\alpha=0.88$ ), Family/relative interaction $(\alpha=0.81)$ and self-interaction and routine interaction ( $\alpha=0.78$ ). The item discrimination analysis showed that, except for items 12 and 35, all the others showed ITC greater than $0.20^{(5,10)}$. Thus, the study on the validation of the instrument was published with 55 of the 62 items, distributed in four dimensions called: Safety, Support, Family Integration, Self, and routine integration, also with satisfactory psychometric properties ${ }^{(5)}$.

Although the CTT does not conflict with the Item Response Theory, they are references used to validate a completely different instrument that can change the results of a study, as evidenced in ECONF. In the TRI, each item is considered independent in the analysis of the instrument, without highlighting the total scores. Thus, the results do not depend exclusively on the test or the questionnaire, but on the behavior of each item that composed $\mathrm{it}^{(11)}$. In the analysis performed by CTT, all items have the same weight and the analysis is performed considering the instrument's total score, to select the best items ${ }^{(12)}$. The completely different paths of analysis in the two theories probably contributed to modify the configuration of ECONF items.

Due to the discrepancy in the number of items involving the two versions of the same instrument, the dimensional structure that did not remain the same (four dimensions in the 55 items version and three in the 46 items version), and the time elapsed for publication, in which many researchers used the original instrument provided 
in thesis formatting, different from the published one, the present study proposed to analyze the psychometric properties of the 46 items version of ECONF and its three dimensions, in relatives of adult and pediatric patients from the state of São Paulo.

\section{OBJECTIVES}

To assess the reliability and validity of the 46 items version of the comfort scale for family members of people in critical condition.

\section{METHODS}

\section{Ethical aspects}

In this study, the guidelines of Resolution №. 510/2016 of the Ministry of Health were followed, in which information collected in a database without the possibility of individual identification is no longer assessed by the system of Research Ethics Committees (CEP) of the country ${ }^{(13)}$, so there is no CAAE.

\section{Design, study location and period}

This is a methodological, observational, cross-sectional, and analytical study of psychometric validation in which an unidentified database was used, with information from family members who responded to ECONF-46. Data were collected from the year 2013 to the year 2016, in the Intensive Care Units (ICUs) of two public hospitals, located in the municipalities of Bauru and Botucatu, in the interior of the state of São Paulo.

At the time of data collection, the ICUs included in the research (two adult ICUs and two pediatric ICUs) did not have an open visit, they were intended for the care of clinical and surgical patients and family members waiting for the daily visit, which was once a day, in the lobby of the units.

\section{Sample, inclusion, and exclusion criteria}

The sample consisted of 278 family members, who were 18 years old and over, with a relative hospitalized in the ICU for more than 48 hours, had self-reported cognitive conditions to answer the questionnaire and were visiting the family member in the ICU.

A total of 208 of the total family members had patients admitted to an adult ICU and, the rest ( $n=70)$, to a pediatric ICU. It should be observed that the different distribution of the sample can be attributed to the fact that it was obtained from different studies carried out with ECONF-46, some of which have already been published ${ }^{(14-15)}$.

The scale was applied to family members of pediatric patients, because although the instrument, in its validation process, was applied only to family members of adult patients, it is intended for family members of pediatric and neonatal critical patients.

\section{Study protocol}

The data, which supported the construction of our database, were collected from 2013 to 2016, using two instruments: the first, was used to collect clinical data from patients and sociodemographic information from family members; and the second instrument was designed to assess the comfort of family members through the ECONF scale with 46 items, distributed in three dimensions: Safety (SAF), Support (SUP) and Family/relative interaction (INT). The approach and invitation to the family member to enroll in the research was carried out in the ICU waiting room (entrance hall), before visiting the patient. The interviews, with up to two members of the same family, were carried out individually in a private environment.

\section{Data analysis}

Initially, Shapiro-Wilk tests were performed to verify the conformity of the scale scores to the normal distribution ${ }^{(16)}$. The analysis procedures included the assessment of construct validity and analysis of the instrument's reliability ${ }^{(17)}$.

To assess the construct validity, the Kaiser-Meyer-Olkin test (KMO) and the Bartlett sphericity test were used to assess, respectively, the adequacy of the data for factorial analysis and the nullity criteria of the correlation among the items of the scale. Horn Parallel Analysis (APH) was used to determine the number of factors/components to be extracted. In APH, the average of the eigenvalues of a hypothetical set of correlation matrices of the items in the scale is calculated, paired and compared with the eigenvalues of the original matrix ${ }^{(18)}$. The number of retained factors must have an eigenvalue $>1$ (Kaiser criterion) and must surpass the respective eigenvalues obtained from the data. APH is considered more accurate than the Kaiser or Cattell criteria ${ }^{(19)}$.

An Exploratory Factorial Analysis (EFA) was performed considering the Kaiser criterion, the factorization method and the type of rotation suggested by the nature of the data. Additionally, EFAs based on the dimensions suggested by the parallel analysis were performed. Factorial loads with an absolute score less than 0.30 and items that presented two or more absolute loads with an absolute difference bellow 0.10 (that is, that show a complex correlation structure) or with communalities after extracting the item below 0.40 were considered negligible ${ }^{(20-22)}$.

The discriminative power of the items was assessed by the item-total correlation, by a Graded Response Model (GRM) and by the factorial loads obtained in the EFA. The GRM is a TRI model specifically developed for ordinal items. The factorial loads assessed the conformity among the three dimensions of the ECONF and the three factors extracted in the EFA. The GRM model provided unidimensional discrimination coefficients $(a)$ for the items. It was standardized that ITC $\leq 0.20$ indicated a negligible correlation and a $0>1$ suggested good item discrimination.

Complementing the construct validity analysis, Confirmatory Factor Analysis (CFA) was used to test the hypothesis that the scale items can be grouped according to the three dimensions indicated, or the three dimensions indicated by the EFA or the dimensions indicated in the parallel analysis. In the process, the statistics Path Diagram, Root-Mean-Square Error (RMSEA), Comparative Fit Index (CFI), Tucker Lewis Index (TLI) were exposed, and a chi-square test of adjustment adequacy was used. In general, $\mathrm{RMSEA} \leq 0.08 ; \mathrm{CFI} \geq 0.90, \mathrm{TLI} \geq 0.90$ and adequacy test with $\mathrm{p} \geq 0.05$ indicate acceptable adjustment ${ }^{(23)}$.

The scale reliability was analyzed using Cronbach's alpha coefficient (a) and McDonald's omega coefficient $(\Omega)$ for the scale items, for the three dimensions suggested by the EFA, for the three dimensions indicated and among the dimensions. The alpha coefficient is based on the variance and covariance of the 
items and values above 0.70 indicate acceptable reliability ${ }^{(24)}$. The omega coefficient is based on the proportion of the variance of the factor loads and, in general, it provides a closer estimate for reliability than the alpha ${ }^{(24)}$, besides, for multidimensional scales, the hierarchical omega is more suitable ${ }^{(16-25)}$.

Considering that the items on the scale are categorical ordinals, in factor analysis, it was decided to use the polychoric correlations and, in correlation analyzes, the ordinal correlation coefficient of Spearman was chosen. In the analyzes, the software $R$ and the Statistical Package for the Social Sciences (SPSS) version 20.0, Windows platform, were used. As a standard, the level of significance was set at 0.05 .

\section{RESULTS}

The sample consisted of 278 adult participants, most of them female $(50.4 \%)$ and with a mean age of 42.8 years old $( \pm 15.1)$. The predominance of family members living with a partner $(80.9 \%)$, Elementary school (42.8\%), Catholics (57.6\%) and economically active $(60.8 \%)$ can be highlighted. According to the results, family members of pediatric patients were significantly younger $(p<0.001)$, had higher income $(p=0.003)$ and less education $(p<0.001)$ than family members of adult patients, Table 1.

Table 1- Sociodemographic characterization of family members of patients admitted to intensive care units in the state of São Paulo, Botucatu, São Paulo, Brazil, from 2013 to 2016

\begin{tabular}{|c|c|c|c|c|c|c|c|}
\hline \multirow[t]{2}{*}{ Variables } & \multicolumn{2}{|c|}{$\begin{array}{c}\text { Total } \\
(\mathrm{N}=\mathbf{2 7 8})\end{array}$} & Ped & $\begin{array}{l}\text { ecruith } \\
\text { atric } \\
U^{*}\end{array}$ & $\begin{array}{r}\text { nent si } \\
\text { Adul }\end{array}$ & t ICU & \multirow[t]{2}{*}{$p$} \\
\hline & $\mathbf{n}$ & $\%$ & $\mathbf{n}$ & $\%$ & $\mathbf{n}$ & $\%$ & \\
\hline $\begin{array}{l}\text { Sex } \\
\text { Male } \\
\text { Female }\end{array}$ & $\begin{array}{l}138 \\
140\end{array}$ & $\begin{array}{l}49.6 \\
50.4\end{array}$ & $\begin{array}{l}41 \\
29\end{array}$ & $\begin{array}{l}58.6 \\
41.4\end{array}$ & $\begin{array}{c}97 \\
111\end{array}$ & $\begin{array}{l}46.6 \\
53.4\end{array}$ & $0.112^{1}$ \\
\hline $\begin{array}{l}\text { Age } \\
\text { Mean }( \pm \mathrm{SD})\end{array}$ & $42.8( \pm$ & $=15.1)$ & 33.6( & $=10.7)$ & 45.9 & $=15.2)$ & $<0.001^{2}$ \\
\hline $\begin{array}{l}\text { Marital status } \\
\text { Unsteady } \\
\text { Steady }\end{array}$ & $\begin{array}{c}53 \\
225\end{array}$ & $\begin{array}{l}19.1 \\
80.9\end{array}$ & $\begin{array}{l}15 \\
55\end{array}$ & $\begin{array}{l}21.4 \\
78.6\end{array}$ & $\begin{array}{c}38 \\
170\end{array}$ & $\begin{array}{l}18.3 \\
81.7\end{array}$ & $0.685^{1}$ \\
\hline $\begin{array}{l}\text { Religion } \\
\text { Non Catholic } \\
\text { Catholic }\end{array}$ & $\begin{array}{l}118 \\
160\end{array}$ & $\begin{array}{l}42.4 \\
57.6\end{array}$ & $\begin{array}{l}33 \\
37\end{array}$ & $\begin{array}{l}47.1 \\
52.9\end{array}$ & $\begin{array}{c}85 \\
123\end{array}$ & $\begin{array}{l}40.9 \\
59.1\end{array}$ & $0.436^{1}$ \\
\hline $\begin{array}{l}\text { Job } \\
\text { Not working } \\
\text { Working }\end{array}$ & $\begin{array}{l}109 \\
169\end{array}$ & $\begin{array}{l}39.2 \\
60.8\end{array}$ & $\begin{array}{l}33 \\
37\end{array}$ & $\begin{array}{l}47.1 \\
52.9\end{array}$ & $\begin{array}{c}76 \\
132\end{array}$ & $\begin{array}{l}36.5 \\
63.5\end{array}$ & $0.153^{1}$ \\
\hline $\begin{array}{l}\text { Income } \\
\text { Did not answer } \\
<1700 \\
>1700\end{array}$ & $\begin{array}{c}12 \\
100 \\
166\end{array}$ & $\begin{array}{c}4.3 \\
36.0 \\
59.7\end{array}$ & $\begin{array}{c}0 \\
17 \\
53\end{array}$ & $\begin{array}{c}0.0 \\
24.3 \\
75.7\end{array}$ & $\begin{array}{c}12 \\
83 \\
113\end{array}$ & $\begin{array}{c}5.8 \\
39.9 \\
54.3\end{array}$ & $0.003^{1}$ \\
\hline $\begin{array}{l}\text { Kinship } \\
\text { Direct } \\
\text { Indirect } \\
\text { None }\end{array}$ & $\begin{array}{l}174 \\
89 \\
15\end{array}$ & $\begin{array}{c}62.6 \\
32.0 \\
5.4\end{array}$ & $\begin{array}{c}51 \\
14 \\
5\end{array}$ & $\begin{array}{l}72.9 \\
20.0 \\
7.1\end{array}$ & $\begin{array}{l}123 \\
75 \\
10\end{array}$ & $\begin{array}{c}59.1 \\
36.1 \\
4.8\end{array}$ & $0.042^{1}$ \\
\hline $\begin{array}{l}\text { Education } \\
\text { Did not answer } \\
\text { Illiterate } \\
\text { Elementary School } \\
\text { High School } \\
\text { Higher Education }\end{array}$ & $\begin{array}{c}1 \\
6 \\
119 \\
109 \\
43\end{array}$ & $\begin{array}{c}0.4 \\
2.2 \\
42.7 \\
39.2 \\
15.5\end{array}$ & $\begin{array}{c}0 \\
0 \\
20 \\
45 \\
5\end{array}$ & $\begin{array}{c}0.0 \\
0.0 \\
28.6 \\
64.3 \\
7.1\end{array}$ & $\begin{array}{c}1 \\
6 \\
99 \\
64 \\
38\end{array}$ & $\begin{array}{l}0.5 \\
2.9 \\
47.5 \\
30.8 \\
18.3\end{array}$ & $<0.001^{1}$ \\
\hline
\end{tabular}

Note: *ICU - Intensive Care Units; ${ }^{2}$ - Pearson Chi-Square2-sided with continuity correction; ${ }^{2}-t$ test for equality of means with equal variances not assumed.

\section{Dimensionality}

Due to the lack of normality of the data and the ordinal categorical nature of the scale items, the APH and factor analyzes were based on the method of the principal axis factoring- PAF, simple oblique rotation (oblimin) and polychoric correlations. The PAF, as a factor analysis method, can distinguish common variance from the specific variance of items, whereas the analysis of main components cannot ${ }^{(18,22,26)}$. Oblique rotation assumes that the factors extracted are correlated and produces similar results to orthogonal methods when the correlation is absent ${ }^{(27)}$. The use of factors over the use of main components is linked to the intent to assess the interrelation among a set of items ${ }^{(26)}$.

Regarding the analysis of the scale's dimensionality, Figure 1 shows the scree plot of the parallel analysis of the ECONF 46 scale's items. The graph allows defining the number of factors and the number of components to be extracted from the scale. The four dotted lines are associated with the main components or factors based on simulated or resampled data. The amount of "-x-" above the upper dotted lines indicates the number of components to be extracted and the quantity of "- $\Delta-$ " above the lower dotted lines indicates the number of factors to be extracted. Thus, the examination of the scree plot allows recommending the extraction of 8 factors and 7 components, indicating the nonunidimensionality of the scale for the individuals under study.

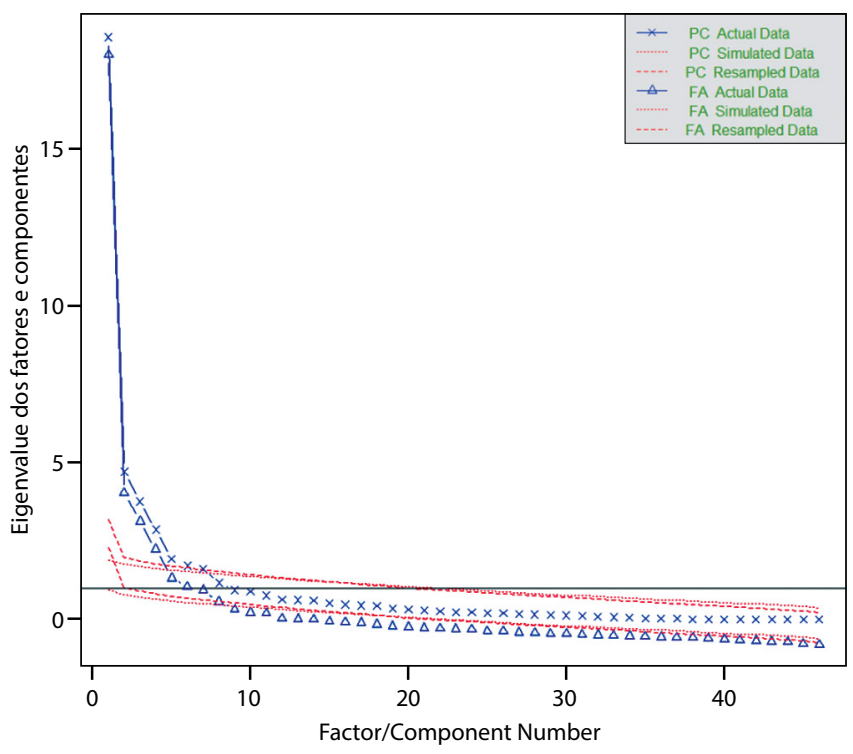

Figure 1 - Parallel analysis of the items

\section{Construct Validity}

Based on the assumption that the scale is not unidimensional, EFA was performed considering the eight suggested factors by the APH and the three recommended factors in the original scale. Regarding the adequacy of the data for the three analyzes, EFA (with eight and with three factors) and with one factor for each of the dimensions postulated in the original scale (Table 2), the KMO values, for all five adjustments, were greater than 0.70 , demonstrating the adequacy of the data for factor analysis. Bartlett's Sphericity Test (TEB) indicated that the 
hypothesis that the items are not correlated with each other should be rejected $(p<0.001)$.

The five adjustments did not show satisfactory performance (RMSEA $>0.10$ ), eight factors extracted explained $74.9 \%$ of the total variation of the items and three explained $56.2 \%$. The subscales (safety, support, and family/relative interaction) explained an insufficient percentage of the total variation. An improvement in these rates would require eliminating more than $22 \%$ of the items on each scale. As a by-product, it is observed that unidimensionality is rejected for each of the three dimensions.

Table 2 - Data adequacy measures for exploratory factorial analysis of the comfort scale for family members of people in critical health condition, Botucatu, São Paulo, Brazil, from 2013 to 2016

\begin{tabular}{|c|c|c|c|c|c|}
\hline \multirow[b]{2}{*}{ Statistics } & \multicolumn{2}{|c|}{46 items } & \multirow[b]{2}{*}{ Safety } & \multirow[b]{2}{*}{$\begin{array}{c}\text { ECONF46* } \\
\text { Support }\end{array}$} & \multirow{2}{*}{$\begin{array}{c}\text { Family/ } \\
\text { relative } \\
\text { interaction }\end{array}$} \\
\hline & $\begin{array}{l}\text { Eight } \\
\text { Factors }\end{array}$ & $\begin{array}{l}\text { Three } \\
\text { Factors }\end{array}$ & & & \\
\hline Number of Items & 46 & 46 & 22 & 18 & 6 \\
\hline $\mathrm{KMO}^{* *}$ & 0.82 & 0.82 & 0.83 & 0.82 & 0.72 \\
\hline $\begin{array}{l}p \text { value of Bartlett's } \\
\text { Sphericity Test. }\end{array}$ & $<0.001$ & $<0.001$ & $<0.001$ & $<0.001$ & $<0.001$ \\
\hline $\begin{array}{l}\text { Numbers of Factors } \\
\text { extracted }\end{array}$ & 8 & 3 & 1 & 1 & 1 \\
\hline $\begin{array}{l}\text { \% Variation } \\
\text { explained by factors }\end{array}$ & 74.9 & 56.2 & 48.6 & 44.9 & 50.2 \\
\hline$\%$ Commonality $<0,4$ & 0 & 13.0 & 22.7 & 33.3 & 50.0 \\
\hline RMSEA $^{\S}$ & 0.501 & 0.457 & 0.209 & 0.282 & 0.203 \\
\hline
\end{tabular}

Note: *ECONF - Comfort Scale for Family Members of People in Critical Health Condition; **KMO - Kaiser Meyer Olkin statistic; ${ }^{5}$ RMSEA - Root Mean Squared Erro.

\section{The Discriminating Power of Items}

Table 3 shows the factorial loads of the tridimensional adjustment based on the EFA referred to in Table 2, the communalities (h2) and the item-total correlations (ITC) associated with the scale items. The examination of the maximum absolute factor load of each item in the table allows grouping such items according to factors F1, F2 and F3, so that F1 is linked to 24 of the 46 items, F2 is linked to 10 of the 46 items and F3 is linked to 12 out of the 46 items. The three factors together explain $56.2 \%$ of the total variation observed in the 46 items.

Concerning the dimensions of safety, support and family/ relative interaction indicated, 16 of the 22 items in the Safety dimension are associated with the F1 factor, 9 of the 18 Support items are associated with the F2 factor, and 5 of the 6 items of the Family/ relative interaction are associated with the $\mathrm{F} 3$ factor, that is, $72.7 \%$ of the security items are associated with F1, $50.0 \%$ of the support items are associated with F2 and $83.3 \%$ of the items of family/ relative interaction are associated with $\mathrm{F} 3$.

When running the AFE with the three factors, it is possible to observe 24 items most associated with Factor 1, with a maximum absolute factorial load varying from 0.34 (item 18_C) to 0.92 (item 15_A), with items Q04_A, 36_B and 18_C are recommended for the exclusion for showing a maximum absolute load less than 0.30 or for showing absolute load very close to each absolute load between the item and another factor (complex correlation structure). The 10 items most associated with Factor 2 exhibited maximum absolute factorial load ranging from 0.38 (35_B) to 0.83 (42_B), with an indication for the exclusion of item 35_B for showing a complex correlation structure. The 12 items associated with Factor 3 exhibited the maximum absolute factorial load varying from 0.38 (46_B) to 0.81 (45_C), an indication of exclusion of item 46_B for showing a complex correlation structure. If we exclude the items based on the criteria of low factor load and complex correlation structure, the items can be grouped according to the factors as follows: Factor 1 (21 items): 02_A, 03_A, 05_A, 06_A, 10_A, 11_A, 13_A, 14_A, 15_A, 16_A, 19_A, 20_A, 24_A, 28_A, 40_A, 07_B, 21_B, 33_B, 34_B, 38_B and 39_B; Factor 2 (9 items): 17_A, 23_B, 25_B, 26_B, 30_B, 32_B, 37_B, 42_B and 44_B; Factor 3 (11 items): 09_A, 12_A, 22_A, 27_A, 43_A, 29_B, 01_C, 08_C, 31_C, 41_C and 45_C.

In the EFA with the eight factors indicated in the parallel analysis, nine items more associated with the MR1 factor were identified, with a maximum absolute factorial load ranging from 0.38 (item 02_A) to 0.83 (item 09_A), with item 02_A receiving the exclusion recommendation for showing a maximum absolute load less than 0.30 and because this load is very close to the absolute load between the item and another factor (in this case, the MR5 factor), thus showing a complex correlation structure. For the nine items associated with the MR2 factor, the maximum absolute loads ranged from 0.47 (23_B) to 0.81 (25_B). For the three items associated with the MR3 factor, the maximum absolute loads were 0.60 (items 41_C and 45_C) and 0.71 (43_A). For the 10 items associated with the MR4 factor, the variation was from 0.42 (14_A) to 0.83 (19_A), with an indication of exclusion of items 03_A, 04_A, 06_A and 14_A as they show a complex correlation structure. For the four items associated with the MR5 factor, the variation was from 0.43 (37_B) to 0.83 (46_B). For the two items associated with the MR6 factor, the maximum absolute loads were 0.61 (28_A) and 0.93 (07_B). For the eight items associated with the MR7 factor, the variation of the absolute maximum load was from 0.8 (items 39_B and 08_C) to 0.85 (38_B), with an indication of exclusion of item 33_B due to low maximum absolute factor load and items 40_A, 33_B, 39_B and 08_C by complex correlation structure. The MR8 factor is associated only with item 13A with an absolute load of 0.56 . If we exclude the items based on the criteria of low factor load and complex correlation structure, the items could be grouped according to the factors as follows: MR1 (8 items):09_A, 12_A, 16_A, 20_A, 22_A, 24_A, 27_A and 29_B; MR2 (9 items): 17_A, 23_B, 25_B, 26_B, 30_B, 32_B, 35_B, 42_B and 44_B; MR3 (3 items): 43_A, 41_C and 45_C; MR4 (6 items): 05_A, 10_A, 11_A, 15_A, 19_A and 18_C; MR5 (4 items): 37_B, 46_B, 01_C and 31_C; MR6 (2 items): 28_A and 07_B; MR7 (4 items):21_B, 34_B, 36_B and 38_B; MR8 (1 item): 13_A.

Concerning specifically to the item's discriminatory capacity, most item-total correlations ranged from 0.28 to 0.68 and the item's discrimination coefficients were greater than 1 , in fact, only item Q08 ("Be able to help your relative to face this situation") and Q43 ("Have available professionals to help your relative") that showed negligible correlations ( $r=0.09$ and $r=0.08$, respectively) and low discriminatory capacity ( $a=0.95$ and $a=0.73$, respectively). The item with the highest absolute correlation with the scale score was the Q30 ("Be treated with kindness at the ICU reception") with a correlation $r=0.68$ and very high discriminatory capacity $(a=1.69)$. Item Q26 ("Being able to relax and/or be distracted during the hospital stay") showed the lowest discriminating capacity ( $a=0.67$ and $r=0.44$ ) and Q20 ("Realize that the team pays attention to your relative's conditions") showed the highest ( $a=3.69$ and $r=0.57$ ). 
Table 3 - Factorial loads, commonality, item-total correlation, and discrimination of items on the comfort scale for family members of people in critical health condition, Botucatu, São Paulo, Brazil, from 2013 to 2016

\begin{tabular}{|c|c|c|c|c|c|c|}
\hline Items & F1 & $\mathbf{F 2}$ & F3 & h2* & ITC** & $a^{* * *}$ \\
\hline \multicolumn{7}{|l|}{ Safety dimension } \\
\hline 02. Receive information about your relative at any time & 0.56 & -0.11 & 0.37 & 0.56 & 0.44 & 2.28 \\
\hline 03.Realize that your relative likes the treatment he/she receives & 0.70 & -0.26 & 0.27 & 0.63 & 0.36 & 1.63 \\
\hline 04.Realize that your relative gets quick treatment when needed & 0.46 & 0.37 & 0.05 & 0.49 & 0.57 & 1.74 \\
\hline 05.Keep your sleeping routine as before your relative's admission & 0.45 & 0.03 & 0.29 & 0.40 & 0.41 & 1.60 \\
\hline 06. Receive a word of support from the team during admission & 0.67 & 0.23 & 0.09 & 0.66 & 0.58 & 3.01 \\
\hline 09.Understand which treatment is being provided to your relative & 0.19 & 0.13 & 0.59 & 0.52 & 0.42 & 1.58 \\
\hline 10.Realize that your relative has received hygiene care & 0.86 & -0.07 & -0.01 & 0.69 & 0.46 & 2.26 \\
\hline 11.Realize that the ICU team offers information cordially & 0.78 & 0.01 & 0.02 & 0.62 & 0.48 & 2.13 \\
\hline 12.Keeping emotionally in control & 0.19 & -0.06 & 0.78 & 0.73 & 0.36 & 1.77 \\
\hline 13.Being able to receive information about your relative when you call & 0.46 & -0.09 & 0.25 & 0.34 & 0.29 & 0.89 \\
\hline 14.Realize the ICU team is interested in knowing how you are doing & 0.66 & -0.37 & 0.44 & 0.75 & 0.30 & 1.87 \\
\hline 15. Hear the truth from professionals about your relative's health condition & 0.92 & -0.19 & 0.02 & 0.78 & 0.48 & 2.69 \\
\hline 16.Be accompanied by a friend or family member during the visit & 0.54 & -0.06 & 0.24 & 0.42 & 0.31 & 1.47 \\
\hline 17. Have available professionals to help your relative & 0.31 & 0.53 & 0.10 & 0.53 & 0.57 & 1.60 \\
\hline 19.Be advised of modifications in the clinical condition of your relative at home & 0.59 & 0.07 & 0.21 & 0.52 & 0.47 & 2.12 \\
\hline 20.Realize that the team pays attention to your relative's conditions & 0.53 & 0.19 & 0.36 & 0.67 & 0.57 & 3.69 \\
\hline 22.Recognize professional competence in those working in the ICU & 0.17 & 0.17 & 0.71 & 0.72 & 0.44 & 2.12 \\
\hline 24.See your relative out of the visiting hours when needed & 0.52 & 0.27 & 0.25 & 0.62 & 0.56 & 3.13 \\
\hline 27.Keep the routine with your family & 0.24 & 0.11 & 0.62 & 0.62 & 0.38 & 2.15 \\
\hline 28.Receive detailed information about your relative's condition & 0.54 & 0.13 & 0.21 & 0.49 & 0.54 & 1.87 \\
\hline 40.Understand that the best possible assistance is being given & 0.48 & 0.34 & 0.19 & 0.58 & 0.62 & 2.69 \\
\hline 43.Realize that ICU professionals understand your situation & 0.11 & -0.09 & 0.51 & 0.30 & 0.08 & 0.73 \\
\hline \multicolumn{7}{|l|}{ Support dimension } \\
\hline 07.Understand that the ICU offers protection for the recovery of your relative & 0.53 & 0.02 & -0.09 & 0.26 & 0.40 & 0.89 \\
\hline 21. Realize that professionals do not insist that you leave at the end of the visit & 0.63 & 0.33 & -0.45 & 0.59 & 0.28 & 0.81 \\
\hline 23. Having a waiting room in the ICU & 0.19 & 0.47 & -0.30 & 0.31 & 0.36 & 0.56 \\
\hline 25.Feel that the team is interested in the recovery of your relative & -0.13 & 0.79 & 0.19 & 0.65 & 0.53 & 0.94 \\
\hline 26.Be able to relax and/or be distracted during the hospital stay & -0.15 & 0.72 & 0.06 & 0.48 & 0.44 & 0.67 \\
\hline 29.Be able to help your relative to face this situation & 0.14 & 0.36 & 0.61 & 0.70 & 0.56 & 2.49 \\
\hline 30.Be treated with kindness at the ICU reception & 0.05 & 0.76 & 0.26 & 0.76 & 0.68 & 1.69 \\
\hline 32.Realize that your relative is responding well to the treatment & 0.02 & 0.66 & 0.26 & 0.59 & 0.54 & 1.31 \\
\hline 33. Have means of distraction in the waiting room (magazine, TV, radio) & 0.54 & 0.37 & 0.10 & 0.63 & 0.55 & 2.52 \\
\hline 34.Believing that faith can help your relative's recovery & 0.72 & 0.23 & -0.15 & 0.62 & 0.59 & 1.91 \\
\hline 35.Continue the usual activities (study, work, leisure, etc.) & 0.34 & 0.38 & 0.25 & 0.51 & 0.53 & 1.80 \\
\hline 36. Have a phone near the waiting room & 0.49 & 0.48 & -0.06 & 0.60 & 0.53 & 1.82 \\
\hline 37.Receive information about what will happen to your relative & -0.16 & 0.82 & 0.16 & 0.66 & 0.60 & 0.92 \\
\hline 38.Understand who are the professionals that can help you when needed & 0.63 & 0.44 & -0.30 & 0.68 & 0.50 & 1.49 \\
\hline 39. Have comfortable furniture in the ICU waiting room & 0.71 & 0.07 & 0.13 & 0.63 & 0.52 & 2.96 \\
\hline 42.Understand that your relative realizes that you are close & 0.09 & 0.83 & 0.07 & 0.78 & 0.66 & 1.45 \\
\hline 44.Realize that you are calmly served by the team & 0.28 & 0.73 & -0.28 & 0.70 & 0.53 & 1.09 \\
\hline 46.Greater number of visitors be allowed when needed & 0.28 & 0.24 & 0.38 & 0.43 & 0.40 & 1.55 \\
\hline \multicolumn{7}{|l|}{ Family/relative interaction dimension } \\
\hline 01.Realize that there is a chance of recovery of your relative & 0.17 & -0.05 & 0.43 & 0.26 & 0.32 & 0.77 \\
\hline 08.See your relative able to talk to you & 0.01 & 0.12 & 0.62 & 0.43 & 0.09 & 0.95 \\
\hline 18. Receive daily information from the doctor & 0.34 & 0.11 & 0.25 & 0.28 & 0.39 & 1.16 \\
\hline 31. Have a place to eat at or near the hospital & -0.04 & 0.28 & 0.62 & 0.50 & 0.32 & 1.28 \\
\hline 41. Realize that the team has patience to listen to family members & 0.07 & 0.31 & 0.57 & 0.54 & 0.42 & 1.53 \\
\hline 45.Receive information from professionals in a way that you can understand & -0.08 & 0.13 & 0.81 & 0.67 & 0.28 & 1.26 \\
\hline \%Variance explained & 24.0 & 16.2 & 16.0 & & & \\
\hline \%Accumulated explained variance & 24.0 & 40.0 & 56.2 & & & \\
\hline
\end{tabular}

Note:*h2 - Communality (sum of factorial loads squares); **ITC - item-total correlation; ***a-alfa,

\section{Confirmatory factorial analysis}

To further examine the structure of ECONF-46, a Confirmatory Factorial Analysis was carried out to verify the scale's tridimensional hypothesis. Figure 2 shows the path diagram that summarizes the analysis. In the diagram, the values linked to the arrows indicate the standardized regression coefficient considering the latent variable (inside the circle) as an independent variable and the manifested variable (inside the square) as a dependent variable, and the values linked to the bidirectional arrows indicate correlations.

Concerning the adequacy of the model to the tridimensional structure (SAF, SUP, INT), two measures of adjustment adequacy were reasonably favorable to the structure $(\mathrm{CFI}=0.92$ and $\mathrm{TLI}=$
$0.916)$ and two were severely unfavorable (RMSEA $=0.166$ and $\mathrm{X}^{2}=8490.54$ with $\left.\mathrm{p}<0.001\right)$. When the data were adjusted to the three dimensions indicated by the EFA, the statistics did not differ much $\left(\mathrm{CFI}=0.93, \mathrm{TLI}=0.93, \mathrm{RMSEA}=0.152\right.$ and $\mathrm{X}^{2}=7273.14$ with $\mathrm{p}<0.001)$, demonstrating that both the three-dimensional model of the authors and the one obtained in the present work show a somewhat obscure behavior regarding the adequacy of the adjustment. An AFC with the dimensional structure indicated in the parallel analysis, with eight factors, produced the statistics CFI $=0.94, \mathrm{TLI}=0.93$, RMSEA $=0.144$ and $x^{2}=5853.9$ with $\mathrm{p}$ $<0.001$. Even if the nine items with maximum factorial loadings below 0.3 or with a complex correlation structure are eliminated, the results will be slightly different from those observed in the 
tridimensional composition of the authors of the original scale or that observed in the EFA.

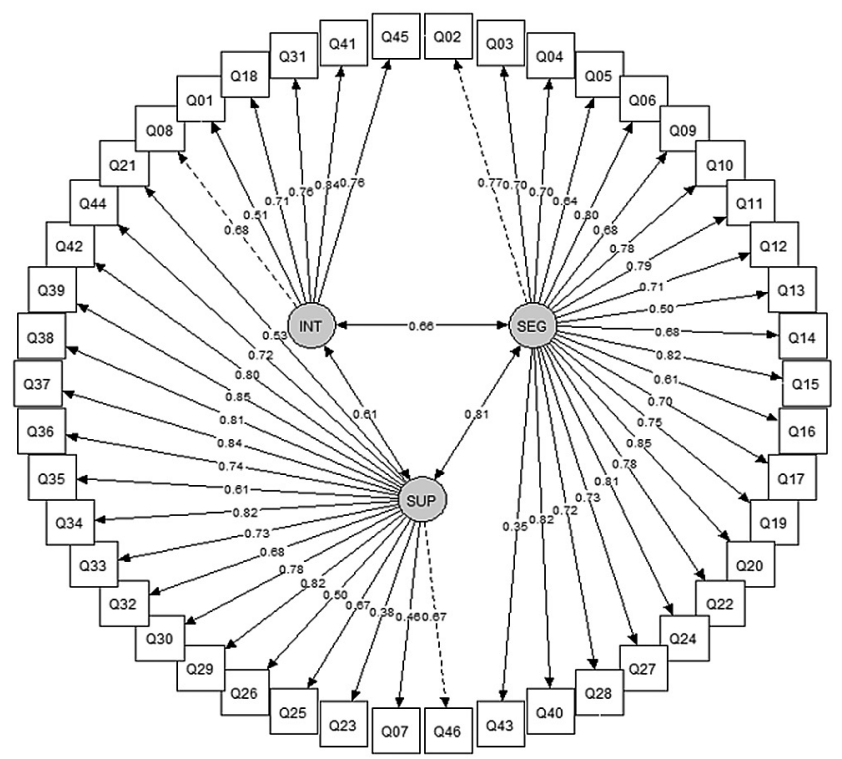

Figure 2 - Path diagram of confirmatory factorial analysis

\section{Reliability}

Considering that the dimensions assumed for ECONF 46 were not sustained, it is possible to conceive them as scales correlated with ECONF 46. With this view, the internal consistency of the items of ECONF 46 and its domains was assessed, through Cronbach's alpha and MacDonald's omega (Table 4), using such values as estimates of the internal consistency of the scales.

The values obtained showed satisfactory internal consistency $(>0.70)$ among the ECONF 46 items (alpha=0.93), among safety items (alpha=0.88), support items (alpha=0.89) and family/relative interaction items the reliability was satisfactory (alpha $=0.72$ ). Unless the scale itself, the omega coefficient indicated a similar result for the dimensions.

Table 4- Distribution of Cronbach's alpha and MacDonald's omega coefficients in the dimensions of ECONF-46* Botucatu, São Paulo, Brazil, from 2013 to 2016

\begin{tabular}{lccc}
\hline Dimensions & $\begin{array}{c}\text { Number } \\
\text { of Items }\end{array}$ & $\begin{array}{c}\text { Cronbach's } \\
\text { Alpha }\end{array}$ & $\begin{array}{c}\text { McDonald's } \\
\text { Omega }\end{array}$ \\
\hline Safety & 22 & 0,88 & 0,95 \\
Support & 18 & 0,89 & 0,93 \\
Family/relative interaction & 6 & 0,72 & 0,85 \\
General & 46 & 0,93 & 0,63 \\
\hline
\end{tabular}

Note: *ECONF-46 - Comfort scale for family members of people in a critical health condition.

\section{DISCUSSION}

Assessing the family members' comfort in the ICU has been a challenge because it is an abstract, subjective, multidimensional concept and for which there is still no consensual definition ${ }^{(28)}$. Thus, the use of accurate, valid, and reliable instruments that assist in this measurement is essential to ensure the reliability of the results obtained.
Before using them, it is crucial to know the items, their domains, how it was built, the forms of assessment and, especially, the measurement properties. Because, the quality of the information provided by them depends, in part, on their good psychometric performance ${ }^{(29-30)}$.

In this context, psychometry is one of the ways of taking measurements through tests that estimate constructs (also called latent variables), that is, characteristics of the individuals that cannot be observed directly ${ }^{(31)}$. According to The Consensus-based Standards for the Selection of Health Measurement Instruments (COSMIN), the properties of a psychometric instrument are structured on three pillars: reliability, validity and responsiveness of the instrument ${ }^{(32)}$.

Considering that responsiveness is "an attribute that refers to validity in the longitudinal context"(20), therefore requiring the application of the scale at many moments, it was not possible to assess this attribute in the present study. Regarding reliability, it is considered one of the main criteria for assessing the quality of an instrument, as it is the ability to reproduce a consistent result ${ }^{(33)}$. In the present investigation, although the omega hierarchical of the total score of the scale is questionable $(\Omega=0.63)$, the observed values of Cronbach's alpha, both in the total score and in the ECONF-46 domains, indicated strong internal consistency, which attests to the instrument's reliability. The results also showed that the internal consistency of the instrument would not be significantly changed either if items were excluded, reinforcing its good reliability.

However, it should be observed that reliability is not a fixed property of a measurement instrument. It is dependent on the function of the instrument, on the public in which it is applied and on the circumstances ${ }^{(34)}$. A fact that contributes to the same instrument is not considered reliable under different conditions, which did not happen in this investigation.

Although Cronbach's alpha is an estimate of consistency based on the magnitude of the covariance of the items, it can be affected by the number of items, questionnaire response alternatives, also to the test's own variance ratio(24). The Omega Coefficient, by using the factorial loads, makes the analysis more stable and provides estimates closer to reliability ${ }^{(35)}$.

To assess the construct's validity of the scale, initially, the dimensionality of the instrument was studied by a Horn parallel analysis, a strategy that compares the eigenvalues of the data factors observed with those of a random data matrix, the same size as the original, it is considered in the literature the most widely used method for retaining factors of an instrument ${ }^{(36)}$. The parallel analysis suggested the removal of 8 factors for the ECONF46 scale, which would indicate a structure with eight dimensions. Results not corroborated with the ECONF-55 validation study, published in 2015, in which this structure for the instrument was not confirmed ${ }^{(5)}$.

In confirmatory factorial analysis under the tridimensional hypothesis of the original scale and the tridimensionality indicated by the EFA used in the present study, the analyzes produced two statistics (CFI and TLI) favorable to the tridimensional structure and two severely unfavorable (chi-square and RMSEA). The result suggests the rejection of the hypothesis that the scale has a tridimensional structure, in fact the parallel analysis showed that the structure should have more than three dimensions. A fact that probably contributed to the scale's authors to improve 
psychometric analysis, which resulted in the four dimensions of the instrument published later.

In AFC when considering the eight dimensions suggested by the parallel analysis, results very similar to those observed in the tridimensional structure were obtained, but these values still do not offer enough evidence to use the instrument with this quantity of dimensions.

However, it should be noted that one of the main limitations of CTT refers to the fact that all analyzes performed are dependent on the sample under study which in turn is influenced by the condition and/or circumstance under which the measurement was completed, besides the individual's ability to understand and respond to the construct investigated ${ }^{(37)}$. Another important point to be considered refers to the rotation procedure of the factor analysis adopted in this investigation (oblique), different from what was used in the ECONF-46 validation process, the orthogonal Varimax.

Orthogonal rotations assume that there is no correlation among the factors, thus generating factors totally independent from each other ${ }^{(18)}$. Although widely used, the literature has shown that this assumption of factor independence adopted by orthogonal rotations is rarely obtained in the areas of health sciences and humanities research, since behaviors, symptoms, attitudes, among other parameters studied are rarely separated on units that work independently from each other ${ }^{(26,38)}$. When working with this type of scale, the basic assumption is that the dimensions of the scale are not only correlated with the investigated construct, but that they are also interrelated with each other, otherwise it would not make sense to call them instrument dimensions.

In this context, there is still not enough evidence to recommend the absolute use of the instrument, whether with three or eight dimensions. It is understood the need for new studies to confirm the dimensional structures initially found, in the perspective of identifying new items that allow improving the current instrument, considering the multidimensionality of the comfort construct.

When it comes to the discriminatory capacity of the items when comparing the dimensions (SEC, SUP, INT) with the factors $(F 1, F 2, F 3)$ through the analysis of the factor loads and the commonality of the ECONF46 items, it was possible to group the 46 items into three factors (F1, F2, F3), which should correspond to the dimensions indicated (SEC, SUP, INT). It was observed that the F1 factor came close to the SEC domain, F2 to the SUP domain and $\mathrm{F} 3$ to the INT domain, but it was not enough to guarantee the instrument's tridimensional structure. A result that can be attributed to the uneven distribution of items in the domains that make up the ECONF-46 and the low variance percentage that the three factors explain (56.2\%).

From the three factors obtained in the analyzed sample, 16 of the 22 items of the Security dimension are associated with factor F1, 9 of the 18 items of Support are associated with factor F2 and 5 of the 6 items of Family/relative interaction are associated with factor $\mathrm{F} 3$, that is, $72.7 \%$ of the safety items are associated with $\mathrm{F} 1,50.0 \%$ of the support items are associated with $\mathrm{F} 2$ and $83.3 \%$ of the family/relative interaction items are associated with F3. Although the structure found is very similar to ECON-46, it is not enough to state that F1 corresponds to Safety, F2 to support and F3 to interaction.
Regarding the item-total correlation of the scale, it was noted that it ranged from very weak to weak $(r=0.28)$, moderate to strong ( $r=0.68$ ), except for items Q08 ("Be able to help your relative to face this situation") and Q43 ("Be able to help your relative to face this situation"). The item that showed the highest absolute correlation with the ECONF46 score was Q30 ("Receive information about the operation of the $\left.I C U^{\prime \prime}\right)$, with $r=0.68$.

When examining the items of the scale, in the context of the EFA with three factors, five items were excluded for showing a maximum absolute load below 0.30 or for showing a complex correlation structure. In the EFA with eight factors, the exclusion of nine items is suggested, following the same analysis criteria. However, AFC with the exclusion of these items did not introduce an important quality gain to the adjustment. A fact that shows the need to review the instrument's items.

Concerning the distribution of response options for each item, given by the 278 family members to the items on the scale, there was a predominance of the "Total comfort" attribution with 49.4\%, together, the options "Very comfortable" or "Totally comfortable" account for $75 \%$ of responses. It is worth mentioning that only $1.1 \%$ of the attributions were "Not comfortable" and 3.3\% were "Not comfortable" or "Not very comfortable".

The high percentage of assignments of the "Very comfortable" or "Totally comfortable" types in the vast majority of items on the scale (42 of 46 items) indicates a pattern of response that may have reduced the discriminative power of the scale's items, a result confirmed by the examination of the $a$ coefficients of the GRM analysis, in which most items show relatively close $a$ values.

It was possible to identify that the items with the most assignments of the type "does not apply" were Q23 ("Have a phone near the waiting room"), Q25 ("Feel that the team is interested in the recovery of your relative"), Q26 ("Being able to relax and/or be distracted during the hospital stay") and Q44 ("Have means of distraction in the waiting room (magazine, TV, radio"). Note that items Q23 and Q44 refer to structural questions of the place where the family member is located, making it possible to infer that the places did not have such infrastructure. The other items represent the individual's perception at the time of the interview, considering all the complexity of the situation experienced in the hospital stay of a family member in the ICU.

Finally, we believe that this investigation adds an important discussion about the instrument's psychometric properties, both in its versions and in this sample. It also highlights the importance of researchers understand the measurement instrument so that they have accurate, valid and understandable data ${ }^{(39)}$. Besides, it shows us that in the process of constructing and validating an instrument, it is essential for researchers to keep a standard of analysis from the beginning, since different paths of psychometric analysis produce divergent results. As psychometric analysis is a vast field of possibilities and analysis, theoretical support is essential to carry out the type of test to be applied.

\section{Study limitations}

One of the limitations of this research is related to the heterogeneity of the sample, since the recruited participants were from two public institutions located in different municipalities in the 
interior of the state of São Paulo, and the data collection took place in four ICUs. Also, the temporal stability of the instrument was not assessed since the data analyzed comes from a database. The scarcity of studies about the comfort of family members of critical patients and the unavailability of another instrument in the literature to measure the construct also made it difficult to compare our results.

\section{Contributions to the Health area}

The study provides relevant information about an instrument that was available for some years in the thesis format, being exclusive in the literature for assessing the comfort of family members of critical patients and whose psychometric analysis does not confirm its dimensional structure, which proves that the psychometric properties of an instrument are not static, but are influenced by the sample under study, the condition and/or situation under which the measurement was performed and, also, by the analysis methods used that are essential for the results' reliability. It is believed that the study also gives way for future research that can contribute to identifying the peculiarities of comfort in the most varied scenarios and carrying out new tests of construct validity.

\section{CONCLUSIONS}

From the analysis of this study, it can be inferred that ECONF-46 presented satisfactory psychometric parameters of reliability and relative construct validity, obtained through confirmatory factor analysis that showed consistent results for the acceptance of the proposed theoretical model in two indexes of the adequacy of the model adjustment, either with three or eight dimensions.

The non-confirmation of the instrument's tridimensional structure shows that the items did not accurately measure the comfort construct of the family members in this sample. In this sense, the evidence points to the need for refining and improving this instrument, so that the dimensional structures applied are confirmed in diverse scenarios. On the other hand, it is necessary to consider that the items of an instrument do not always show the expected behavior, whether for reasons inherent to the research participant, the absence of a theoretical connection among the items and the construct under study and/or even the path itself of psychometric analysis that can be performed in different software.

However, it should be observed that in this study, when possible, the same path of psychometric analyzes performed in the original validation of the instrument was followed, and the sample size was considered adequate to give precision to the results.

\section{REFERENCES}

1. Kolcaba KY. A theory of holistic comfort for nursing. J Adv Nurs. 1994;19(6):1178-84. https://doi.org/10.1111/j.1365-2648.1994.tb01202.x

2. Freitas KS, Menezes IG, Mussi FC. Comfort from the perspective of families of people hospitalized in the Intensive Care Unit. Texto Contexto Enferm. 2012;21(4):896-904. http://dx.doi.org/10.1590/S0104-07072012000400021

3. Ponte KMA, Silva LDF. Comfort as a result of nursing care: an integrative review. Rev Pesqui Cuid Fundam. 2015;7(2):2603. https://doi. org/10.9789/2175-5361.2015.v7i2.2603-2614

4. Høghaug G, Fagermoen MS, Lerdal A. The visitor's regard of their need for support, comfort, information proximity and assurance in the intensive care unit. Intens Crit Care Nurs. 2012;28(5):263-8. https://doi.org/10.1016/j.iccn.2011.11.009

5. Freitas KS, Menezes IG, Mussi FC. Validation of the Comfort scale for relatives of people in critical states of health. Rev Latino-Am Enfermagem. 2015;23(4):660-8. https://doi.org/10.1590/0104-1169.0180.2601

6. Fumis RRL, Ranzani OT, Martins PS, Schettino G. Emotional disorders in pairs of patients and their family members during and after ICU stay. PLoS One. 2015;10(1):e0115332. https://doi.org/10.1371/journal.pone.0115332

7. Puggina AC, lenne A, Carbonari KFBS da F, Parejo LS, Sapatini TF, Silva MJP. Perception of communication, satisfaction and importance of family needs in the Intensive Care Unit. Escola Anna Nery. 2014;18(2):277-83. https://doi.org/10.5935/1414-8145.20140040

8. Apóstolo JLA. Comfort in nursing theories: concept analysis and theoretical meaning. Ver Enf Ref. 2009;(9):61-7.

9. Paiva BSR, Carvalho AL, Kolcaba K, Paiva CE. Validation of the Holistic Comfort Questionnaire-caregiver in Portuguese-Brazil in a cohort of informal caregivers of palliative care cancer patients. Support Care Cancer. 2015;23(2):343-51. https://doi.org/10.1007/s00520-014-2370-5

10. Freitas KS. Construção e validação da escala de conforto para familiares de pessoas em estado crítico de saúde (ECONF) [Tese]. Universidade Federal da Bahia; 2012.

11. Yang FM, Kao ST. Item response theory for measurement validity. Shanghai Arch Psychiatr. 2014;26(3):171-7. https://doi.org/10.3969/j. issn.1002-0829.2014.03.010

12. Sartes LMA, Souza-Formigoni MLO. Advances in psychometrics: from Classical Test Theory to Item Response Theory. Psicol Reflex Crit. 2013;26(2):241-50. https://doi.org/10.1590/S0102-79722013000200004

13. Ministério da Saúde (BR). Conselho Nacional de Saúde. Resolução no. 510 de 07 de abril de 2016. Brasília(DF); 2016.

14. Meneguin S, Pollo CF, Benichel CR, Cunha LK, Miot HA. Comfort and religious-spiritual coping of intensive care patients' relatives. Intensive Crit Care Nurs. 2020;58:102805. https://doi.org/10.1016/j.iccn.2020.102805

15. Meneguin S, Souza Matos TD, Miot HA, Pollo CF. Association between comfort and needs of ICU patients' family members: a cross-sectional study. J Clin Nurs. 2019;28(3-4):538-44. https://doi.org/10.1111/jocn.14644 
16. Stephens MA. EDF Statistics for Goodness of Fit and Some Comparisons. J Am Statistic Assoc. 1974;69(347):730-7. https://doi. org/10.2307/2286009

17. Salmond SS. Evaluating the reliability and validity of measurement instruments. Orthop Nurs. 2008;27(1):28-30. https://doi.org/10.1097/01. NOR.0000310608.00743.54

18. Damásio BF. Uso da análise fatorial exploratória em psicologia. Aval psicol. 2012;11(2):213-28. Available from: http://pepsic.bvsalud.org/pdf/ avp/v11n2/v11n2a07.pdf

19. Ledesma RD, Valero-Mora P. Determining the Number of Factors to Retain in EFA: An easy-to-use computer program for carrying out Parallel Analysis. 2007;12(2). https://doi.org/https://doi.org/10.7275/wjnc-nm63

20. Coluci MZO, Alexandre NMC, Milani D. Construção de instrumentos de medida na área da saúde. Ciênc Saúde Coletiva. 2015;20(3):925-36. https://doi.org/10.1590/1413-81232015203.04332013

21. Kaiser HF. An index of factorial simplicity. Psychometrika. 1974;39(1):31-6. https://doi.org/10.1007/BF02291575

22. Figueiredo Filho DB, Silva Jr JA. Visão além do alcance: uma introdução à análise fatorial. Opin Publica. 2010;16(1):160-85. http://dx.doi. org/10.1590/S0104-62762010000100007

23. Anunciação L. An overview of the history and methodological aspects of psychometrics. JRTDD. 2018;1:44. https://doi.org/10.26407/2018jrtdd.1.6

24. Sijtsma K. On the use, the misuse, and the very limited usefulness of Cronbach's Alpha. Psychometrika. 2009;74(1):107-20. https://doi. org/10.1007/s11336-008-9101-0

25. Zinbarg RE, Revelle W, Yovel I, Li W. Cronbach's a, Revelle's $\beta$, and Mcdonald's $\omega H$ : their relations with each other and two alternative conceptualizations of reliability. Psychometrika. 2005;70(1):123-33. https://doi.org/10.1007/s11336-003-0974-7

26. Costello $A B$, Osborne J. Best practices in exploratory factor analysis: four recommendations for getting the most from your analysis. Pract Assessm, Res, Evaluation. 2005;10(7). https://doi.org/https://doi.org/10.7275/jyj1-4868

27. Fabrigar LR, Wegener DT, MacCallum RC, Strahan EJ. Evaluating the use of exploratory factor analysis in psychological research. Psychol Methods. 1999;4(3):272-99. https://doi.org/10.1037/1082-989X.4.3.272

28. Meneguin S, Nobukuni MC, M. Bravin SH, Benichel CR, Dionísio de Souza Matos T. O significado de conforto na perspectiva de familiares de pacientes internados em UTI. Nursing. 2019;22(252):2882-6. https://doi.org/10.36489/nursing.2019v22i252p2882-2886

29. Hair JF, Anderson RE, Tatham RL, Black WC. Análise multivariada de dados. 5th ed. Porto Alegre: Artmed; 2005.

30. Norris $\mathrm{M}$, Lecavalier L. Evaluating the use of exploratory factor analysis in developmental disability psychological research. J Autism Dev Disord. 2010;40(1):8-20. https://doi.org/10.1007/s10803-009-0816-2

31. Barrientos-Trigo S, Gil-García E, Romero-Sánchez JM, Badanta-Romero B, Porcel-Gálvez AM. Evaluation of psychometric properties of instruments measuring nursing-sensitive outcomes: a systematic review. Int Nurs Rev. 2019;66(2):209-23. https://doi.org/10.1111/inr.12495

32. Mokkink LB, Terwee CB, Patrick DL, Alonso J, Stratford PW, Knol DL, et al. The COSMIN checklist for assessing the methodological quality of studies on measurement properties of health status measurement instruments: an international Delphi study. Qual Life Res. 2010;19(4):539-49. https://doi.org/10.1590/bjpt-rbf.2014.0143

33. Fayers PM, Machin D. Quality of life: the assessment, analysis, and interpretation of patient reported outcomes. 2nd ed. Chichester: J Wiley; 2007.

34. Keszei AP, Novak M, Streiner DL. Introduction to health measurement scales. J Psychosom Res. 2010;68(4):319-23. https://doi.org/10.1016/j. jpsychores.2010.01.006

35. Ventura-León, José Luis, Caycho-Rodríguez, Tomás. El coeficiente Omega: un método alternativo para la estimación de la confiabilidad. Rev Latinoamericana Cienc Soc, Niñez Juv [Internet]. 2017[cited 2020 Jun 02];15(1):625-27. Available from: https://www.redalyc.org/articulo. oa?id=77349627039

36. Horn JL. A rationale and test for the number of factors in factor analysis. Psychometrika. 1965;30(2):179-85. https://doi.org/10.1007/ BF02289447

37. Bichi AA. Classical Test Theory: an introduction to linear modeling approach to test and item analysis. Int J Soc Stud [Internet]. 20 ed 2016[cited 2020 Jun 02]. Available from: https://www.researchgate.net/ publication/317012320_CLASSICAL_TEST_THEORY_An_Introduction_to_Linear_Modeling_Approach_to_Test_and_Item_Analysis

38. Schmitt TA, Sass DA. Rotation criteria and hypothesis testing for exploratory factor analysis: implications for factor pattern loadings and interfactor correlations. Educ Psychol Measurem. 2011;71(1):95-113. https://doi.org/10.1177/0013164410387348

39. Alexandre NMC, Gallasch CH, Lima MHM, Rodrigues RCM. A confiabilidade no desenvolvimento e avaliação de instrumentos de medida na área da saúde. Rev Eletron Enf. 2013;15(3):800-7. https://doi.org/10.5216/ree.v15i3.20776 